\title{
Effect of Initial Grain Size on Thermal Fatigue Behavior and Changes in Microstructure of Ferritic Stainless Steel
}

\author{
Jun-ichi Hamada*1,*2 and Chikako Takushima*2 \\ Research \& Development Center, NIPPON STEEL Stainless Steel Corporation, Hikari 743-8550, Japan
}

To understand the effect of grain size on the thermal fatigue behavior and dynamic recrystallization during the thermal fatigue process in ferritic stainless steel, interrupted testing of thermal fatigue in the temperature range from $473 \mathrm{~K}$ (minimum) to $1073 \mathrm{~K}$ (maximum) with a restriction ratio of $50 \%$ was conducted for fine-grained (diameter: $38 \mu \mathrm{m}$ ) and coarse-grained (diameter: $221 \mu \mathrm{m}$ ) specimens in a Nb- and Si-added ferritic stainless steel tube. The fine-grained specimen showed a small inelastic strain range during the thermal fatigue process and a longer life than the coarse-grained specimen. Microstructure observation by electron back-scatter diffraction revealed that dynamic recovery and recrystallization occurred during the thermal fatigue process. However, the coarse-grained specimen showed lower nucleus density and retardation of the recrystallization in comparison with the fine-grained specimen. From a supposition of the accumulation of the inelastic strain range during thermal fatigue cycles, the relationship between the accumulation strain and Zener-Hollomon parameter for dynamic recovery and recrystallization almost accorded with previous knowledge on this tendency. In addition, we found that for the steady-state recrystallized grain size in thermal fatigue cycles, there was little initial grain size dependence. [doi:10.2320/matertrans.M2018382]

(Received December 10, 2018; Accepted February 18, 2019; Published April 25, 2019)

Keywords: ferritic stainless steel, thermal fatigue, grain size, dynamic recovery, dynamic recrystallization, grain refinement, misorientation, Zener-Hollomon parameter

\section{Introduction}

Control of the microstructure and grain refinement through thermo-mechanical processing has been recognized to contribute to improving the characteristics of numerous materials. ${ }^{1-7)}$ Recrystallization is the most basic principle for grain refinement in steel, along with phase transformation. Dynamic restoration by recovery and recrystallization is caused by the introduction, disappearance, and rearrangement of dislocations during high-temperature deformation. Control of the grain size by dynamic recrystallization during hightemperature deformation is possible by modifying the processing conditions, e.g., temperature and strain rate. In ferritic steels, dynamic recovery is mainly thought to occur during high-temperature deformation. Several reports have clarified the mechanism of dynamic recrystallization. ${ }^{8-12)}$ Research by Tsuji et al. ${ }^{11,12)}$ clarified that dynamic recrystallization occurred when ferritic steel was compressively deformed under the condition of a relatively low ZenerHollomon parameter $(Z)$. In the experiments concerning dynamic recrystallization in previous studies, tension, compression, and torsion tests at high temperatures were performed, and considerably high deformation was important for producing a very fine-grained structure.

In contrast, for heat-resistant ferritic stainless steel applied to automotive exhaust system parts, the most important characteristic is thermal fatigue because the material is subjected to many thermal and strain cycle conditions because of the exhaust gas and engine operation. ${ }^{13)}$ In studies $^{14,15)}$ on thermal fatigue wherein the temperature and strain change repeatedly in ferritic stainless steels, dynamic recrystallization was found to occur during the thermal

\footnotetext{
${ }^{* 1}$ Corresponding author, E-mail: hamada.junichi.4m8@stainless.nipponsteel. com

${ }^{* 2}$ Formerly at Research \& Development Center, Nippon Steel \& Sumikin Stainless Steel Corporation
}

fatigue process and a relationship was identified between misorientation and thermal fatigue damage. However, the influence of the initial grain size is expected to change the behavior and the microstructure during thermal fatigue. Therefore, the present study investigated the effect of the initial grain size on the life, stress and strain response, and dynamic recrystallization during the thermal fatigue process of representative heat-resistant ferritic stainless steel.

\section{Experimental Procedures}

\subsection{Specimen preparation}

A heat-resistant ferritic stainless steel tube $(13.3 \% \mathrm{Cr}-$ $0.47 \% \mathrm{Nb}-0.86 \% \mathrm{Si}-0.004 \% \mathrm{C}-0.008 \% \mathrm{~N} ; \quad \varphi 38.1 \times 2 \mathrm{~mm}$ thick) was used as the test material. ${ }^{15)}$ Conventionally, various types of steel have been developed as heat-resistant ferritic stainless steel for fabricating automotive exhaust manifold systems. ${ }^{16-19)}$ The used steel is one of the representative steels. We added $\mathrm{Nb}$ and $\mathrm{Si}$ to the steel tube for improving its high-temperature strength, thermal fatigue, and oxidation characteristics. To obtain specimens with different grain sizes, the materials were subjected to different heat treatments before the thermal fatigue test. The specimen subjected to heat treatment at $1223 \mathrm{~K}$ for $30 \mathrm{~s}$, followed by air-cooling, was considered to be a fine-grained material. Another specimen subjected to heat treatment twice, once at $1423 \mathrm{~K}$ for $30 \mathrm{~s}$ and then at $1223 \mathrm{~K}$ for $30 \mathrm{~s}$, each followed by air-cooling, was considered to be a coarse-grained material. Figure 1 shows the microstructures of the materials viewed using an optical microscope. Both materials were ferrite single-phase recrystallized structures, and the average grain diameters of the fine- and coarse-grained specimens were 38 and $221 \mu \mathrm{m}$, respectively. In addition, the measured Vickers hardness (1 kgf) at the center layer of the tube was 150 and 140 , respectively, for the fine- and coarse-grained specimens; the hardness of the former was higher owing to the effect of the grain size. 


\section{个Thickness direction Axial direction}
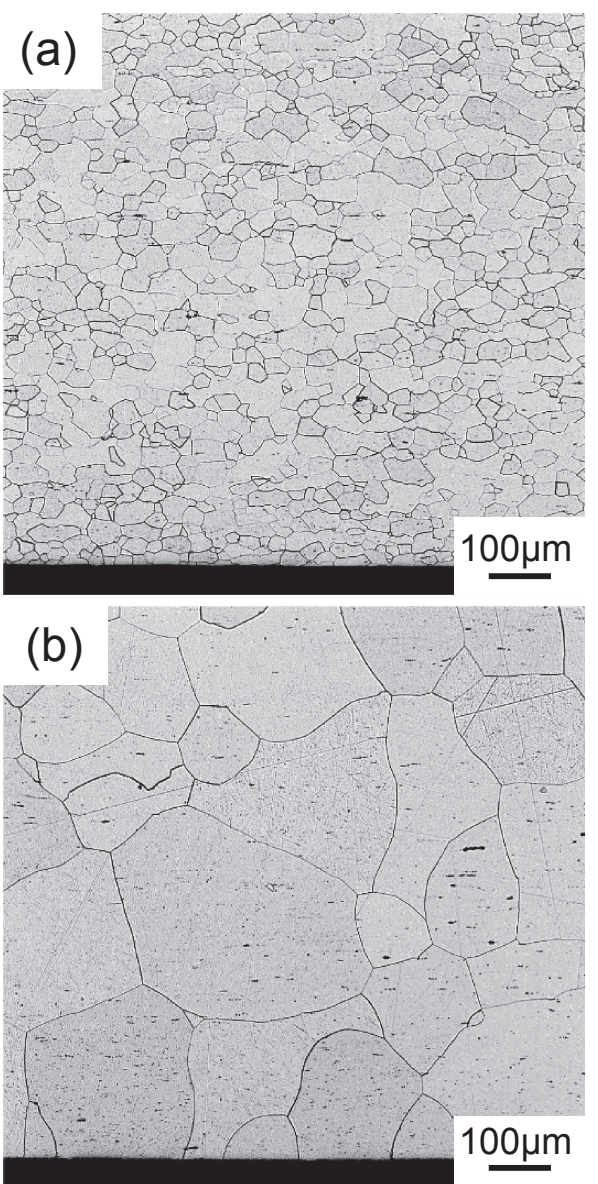

Fig. 1 Optical microstructures of materials with (a) fine grains and (b) coarse grains

\subsection{Thermal fatigue test}

As in previous studies, ${ }^{14-16)}$ a thermal fatigue test using a tube specimen was conducted with a controlled restriction ratio and with the aid of a servo-hydraulic testing machine and a heating and cooling system for controlling the temperature profile with assistance from a computer. The tube specimen has a length of $170 \mathrm{~mm}$, and has a structure allowing air passage through the hollow part of length $40 \mathrm{~mm} .{ }^{14-16)}$ Figure 2 shows the waveforms of the temperature and mechanical strain range acting on the materials in two cycles. Here, the stain range on the basis of the strain at $473 \mathrm{~K}$ (minimum temperature) is assumed to be the mechanical strain range. The specimen was heated to $1073 \mathrm{~K}$ at a heating speed of $4 \mathrm{~K} / \mathrm{s}$ from outside with a highfrequency induction heating system and held at $1073 \mathrm{~K}$ for $30 \mathrm{~s}$. Then, it was cooled to $573 \mathrm{~K}$ at a cooling speed of $4 \mathrm{~K} / \mathrm{s}$ and to $473 \mathrm{~K}$ at a cooling speed of $1 \mathrm{~K} / \mathrm{s}$ later via output control of the high-frequency induction heating and ventilation from the inside of the tube. The strain in the tube axis direction was measured using an extensometer with a gauge length of $12 \mathrm{~mm}$, and the temperature distribution within the gauge length was adjusted within $\pm 5 \mathrm{~K}$ including the circumferential direction. The temperature and axial strain of the specimen were synchronized so that the axial

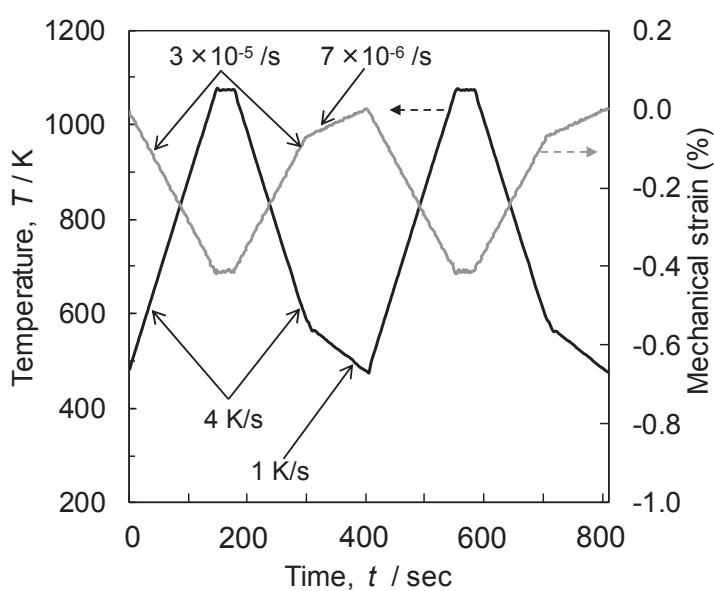

Fig. 2 Waveforms of temperature and mechanical strain in 2 cycles.

restriction ratio for free thermal expansion became constant (i.e., 50\%) at each temperature during the heat cycle. Therefore, a compression strain acted on the material and the strain rate was approximately $7 \times 10^{-6}$ and $3 \times 10^{-5} \mathrm{~s}^{-1}$ in each temperature range. The examination was interrupted at 300,500 , and 700 cycles before thermal fatigue life.

\subsection{Microstructural observation}

Microstructural observations of the inside of the tube at the center along the axial direction of the interrupted and fractured specimens were conducted using optical microscopy and electron back-scatter diffraction (EBSD) with field emission scanning electron microscopy (acceleration voltage: $25 \mathrm{kV}$; beam step: $1 \mu \mathrm{m})$.

\section{Results and Discussion}

\subsection{Thermal fatigue behavior}

Examination was conducted for 1174 and 1000 cycles for the fine- and coarse-grained specimens, respectively, and the penetration of the crack was confirmed in the abovementioned cycles. Figure 3 shows the changes in the maximum and minimum stress with an increase in the number of thermal fatigue cycles. Both specimens showed softening with an increase in the number of thermal fatigue

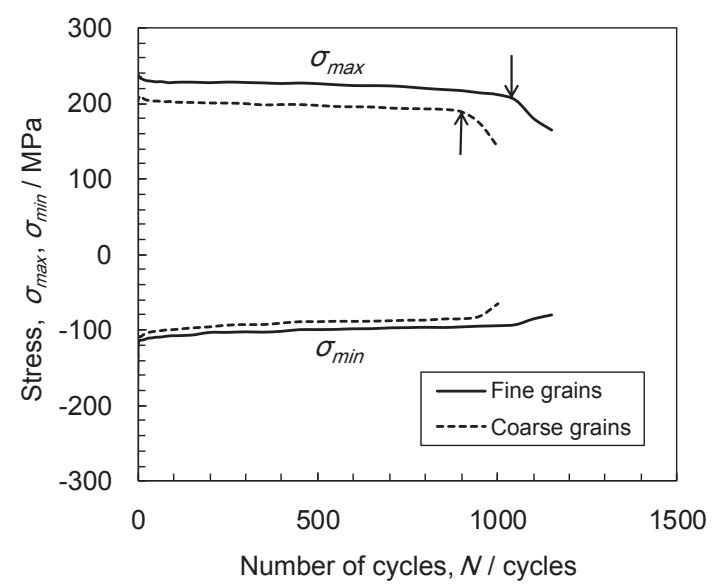

Fig. 3 Changes in the maximum and minimum stress with an increase in the number of thermal fatigue cycles. 
(a)

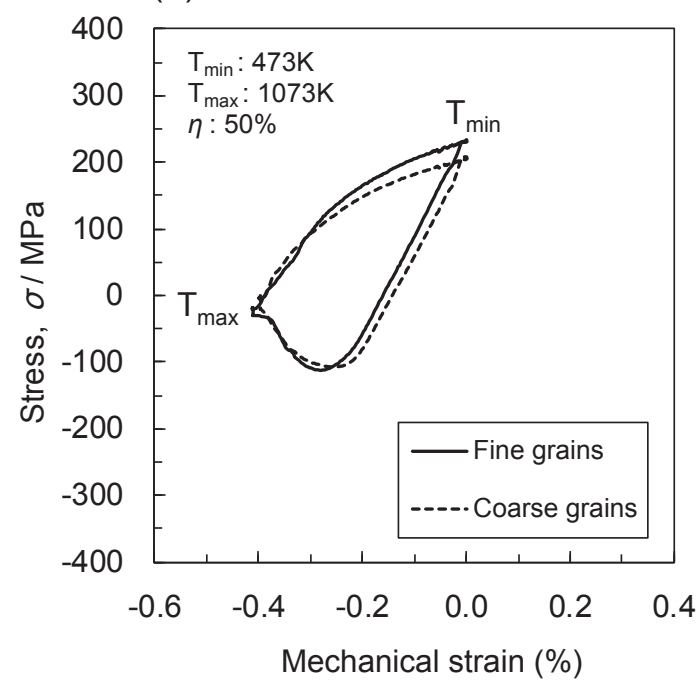

(b)

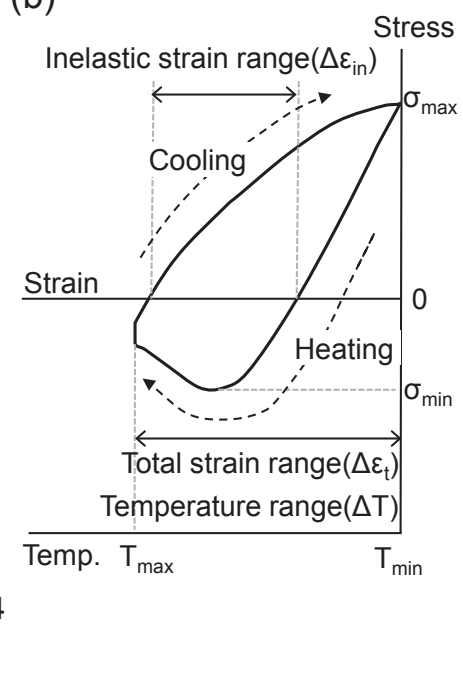

Fig. 4 (a) Hysteresis loops in tenth cycle for the specimens with fine and coarse grains. (b) Illustration of the hysteresis loop.

cycles, and this behavior was similar to that reported in a previous study; ${ }^{15)}$ however, the stress of the fine-grained specimen was higher than that of the coarse-grained specimen. In this figure, the inflection points at which the stress suddenly decreases are indicated by arrows; for the fine- and coarse-grained specimens, the number of cycles is 1024 and 891, respectively. In this study, the inflection points were considered the life cycle. From this result, it was recognized that the fine-grained material had a longer life than the coarse-grained material in this experimental condition.

As representative hysteresis loops indicating the response of stress and strain during thermal fatigue examination, Fig. 4 shows the hysteresis loops in tenth cycle. Compression strain occurred during the heating cycle, and compression and tensile stress occurred during heating and cooling, respectively. Although the total mechanical strain range per cycle was approximately $0.41 \%$ by nominal strain in both specimens, the inelastic stain range of the fine-grained specimen was slightly smaller than that of the coarse-grained specimen. Specifically, the inelastic strain ranges for the fineand coarse-grained specimens were $0.22 \%$ and $0.25 \%$, respectively. During cooling, the fine-grained specimen showed higher tensile stress in comparison with the coarsegrained specimen. From previous studies, the thermal fatigue life is known to increase with a decrease in the inelastic strain range. ${ }^{14,20)}$ Because the fine-grained specimen has a higher hardness at room temperature, it is hypothesized that the strength in the relatively low-temperature range in the thermal fatigue process from $473 \mathrm{~K}$ to $1073 \mathrm{~K}$ influenced the difference of the inelastic strain range by the initial grain size. This difference may influence the thermal fatigue life.

\subsection{Microstructures}

Figure 5 shows the changes in microstructures during thermal fatigue using an optical microscope. Compared to the microstructure before the test shown in Fig. 1, grain refinement occurred with increasing number of cycles. In particular, grain refinement was remarkable after 1174 cycles for the fine-grained specimen. In contrast, for the coarsegrained specimen, inhomogeneous microstructures and unclear grain boundaries were observed. A magnified image after 700 cycles for the coarse-grained specimen is shown in Fig. 6. Numerous fine grains were observed in the initial grain interiors, and grain refinement was also confirmed for the coarse-grained specimen. However, most new grain boundaries were indistinct at this stage. A magnified image of the coarse-grained specimen after 300 cycles is shown in Fig. 7. It can be seen that plastic deformation occurs heterogeneously and that deformation bands develop in the grain interiors. These deformation bands are equivalent to a micro-shear band and lead to the rotation and formation of new fine grains. ${ }^{3}$ )

\subsection{Changes in grain boundaries}

To determine the grain boundary characteristics during the thermal fatigue process, the grain boundary maps in Fig. 8 of the (a and f) initial, (b-d and g-h) interrupted, and (e and j) fractured specimens with $(\mathrm{a}-\mathrm{e})$ fine grains and $(\mathrm{f}-\mathrm{j})$ coarse grains were studied. In this figure, red lines denote low-angle grain boundaries with a misorientation angle of $2^{\circ}$ or more and less than $15^{\circ}$, and black lines denote high-angle grain boundaries with a misorientation angle of more than $15^{\circ}$. In the case of fine-grained specimens, many subgrains with lowangle boundaries were clearly observed in the initial highangle grain interior after 300 cycles. With the progress of the thermal fatigue cycling, very fine grains with a high-angle boundary formed and grain refinement was promoted. This result is similar to that of a previous study, ${ }^{15)}$ and it is recognized that dynamic recrystallization, accompanied by uniaxial and fine grain formation occurred during the thermal fatigue process. Moreover, in consideration of previous study, ${ }^{15)}$ the characteristics of formation of subgrains and the equaxed fine grains having high-angle boundary in the initial high-angle grain interior is similar to the feature of continuous recrystallization. ${ }^{21)}$ Although it can not be concluded whether dynamic recrystallization in this experiment is strictly "continuous" or "discontinuous", since the 

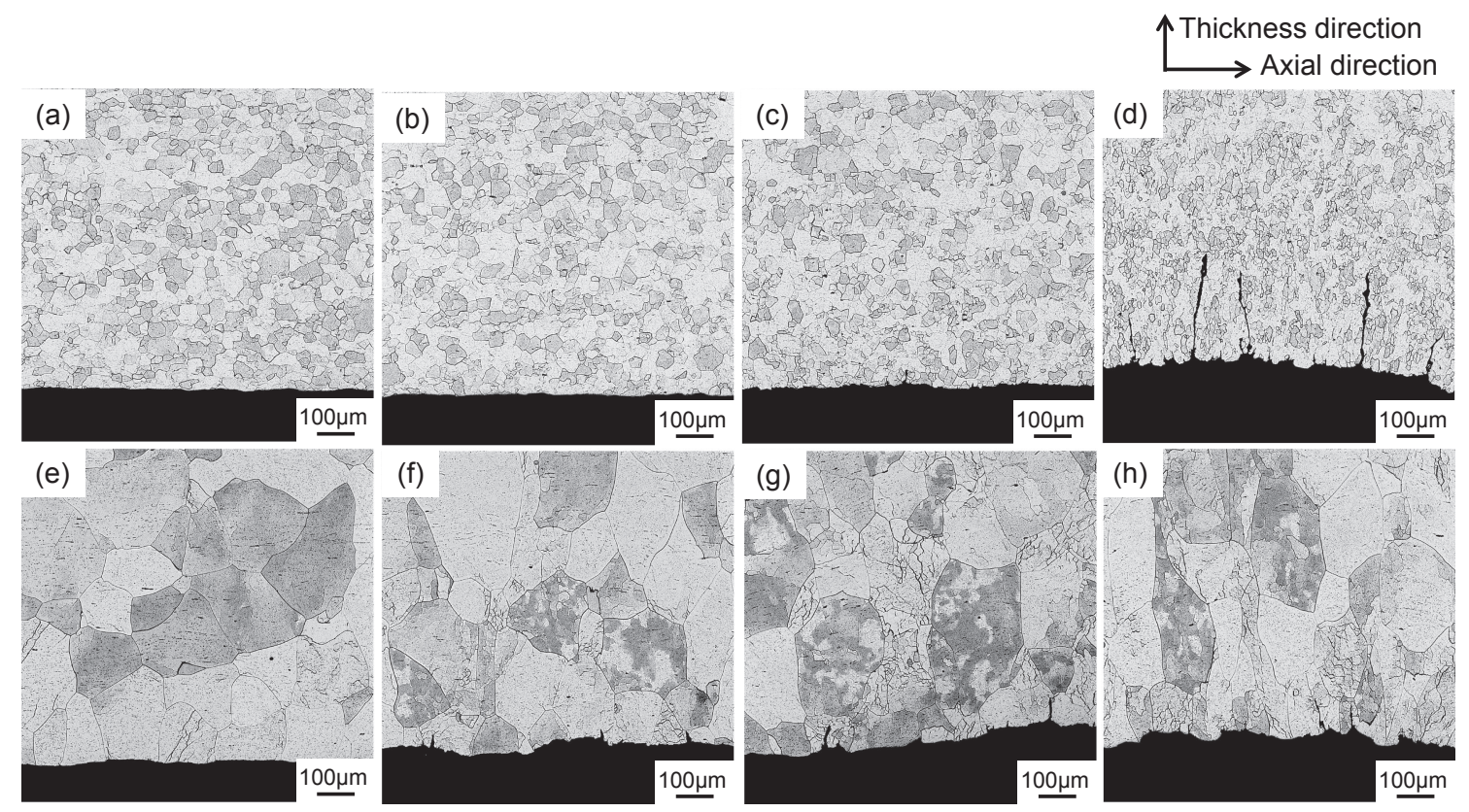

Fig. 5 Optical microstructures for the specimens with $(\mathrm{a}-\mathrm{d})$ fine grains and $(\mathrm{e}-\mathrm{h})$ coarse grains. (a, e) Observation after 300 cycles (b, f) Observation after 500 cycles. (c, g) Observation after 700 cycles. (d, h) Observation after 1174 and 1000 cycles, respectively.

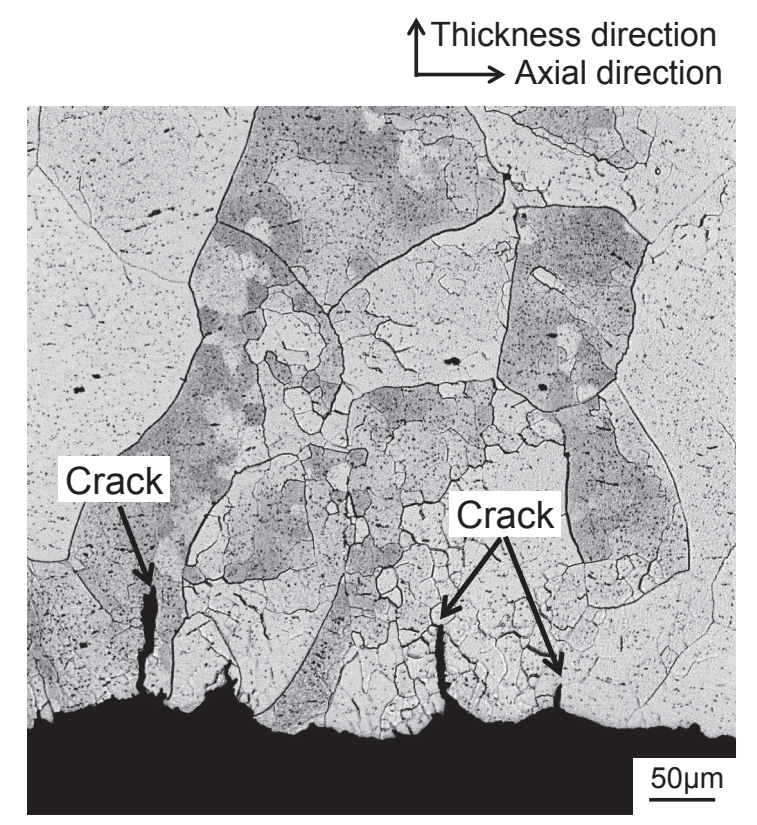

Fig. 6 Optical microstructure after 700 cycles for a specimen with coarse grains.

difference in grain size between new grains and subgrains is small, it seems to be closer to "continuous" recrystallization than "discontinuous" in which specific grains grow. ${ }^{15)}$ However, in the case of the coarse-grained specimen, after 300 cycles, low-angle boundaries were formed in the initial grain interiors, but the formation was inhomogeneous and the rate of subgrain formation was lower than that observed in the case of fine-grained specimens. For the coarse-grained specimen, after 500 cycles, subgrains were clearly observed in the initial grain interior. Figure 9(a) shows an inverse pole figure map of the axial direction obtained via EBSD measurements for the coarse-grained specimen interrupted at 500 cycles, and Fig. 9(b) indicates the expected initial grain

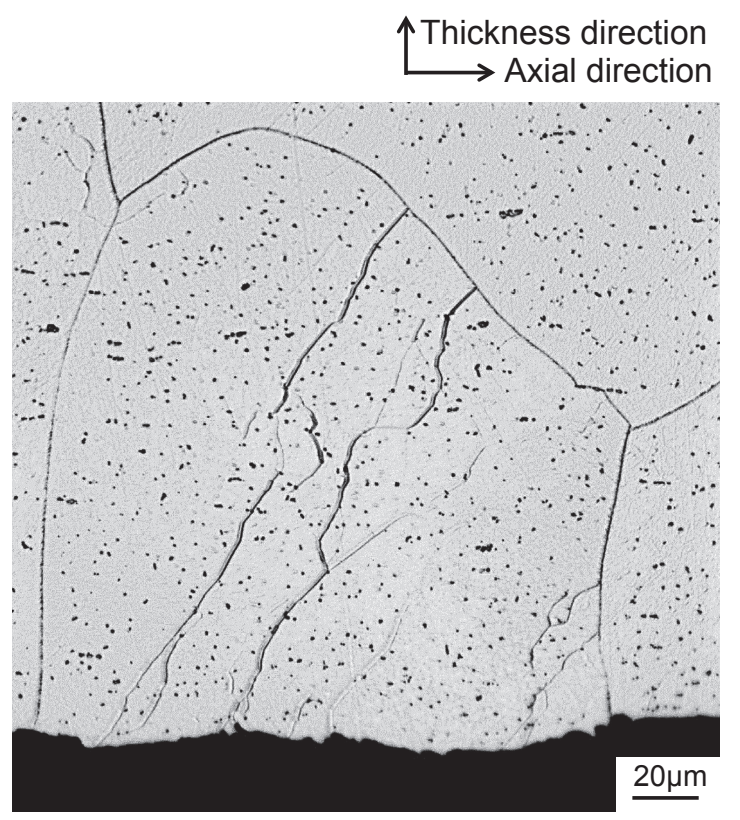

Fig. 7 Optical microstructure after 300 cycles for a specimen with coarse grains.

boundaries in Fig. 9(a). In the initial grain interior, numerous low- and high-angle boundaries were recognized. In addition, rotation of the crystal orientation occurred at the location indicated by the black arrows. Moreover, subgrains were found to have formed easily near high-angle grain boundaries. Furthermore, we found that the nucleation of new grains with a low-angle boundary similar to a "necklace" structure partially occurred at or near the pre-existing grain boundary indicated by the thick white arrows in this figure. Because the necklace-like structure in dynamic discontinuous recrystallization is generally observed due to a large difference in the size between the initial and new grain sizes and has high-angle boundary. ${ }^{1,3-6)}$ Thus, the "necklace" 
Boundary levels: red line $<15^{\circ}$, black line $\geqq 15^{\circ}$
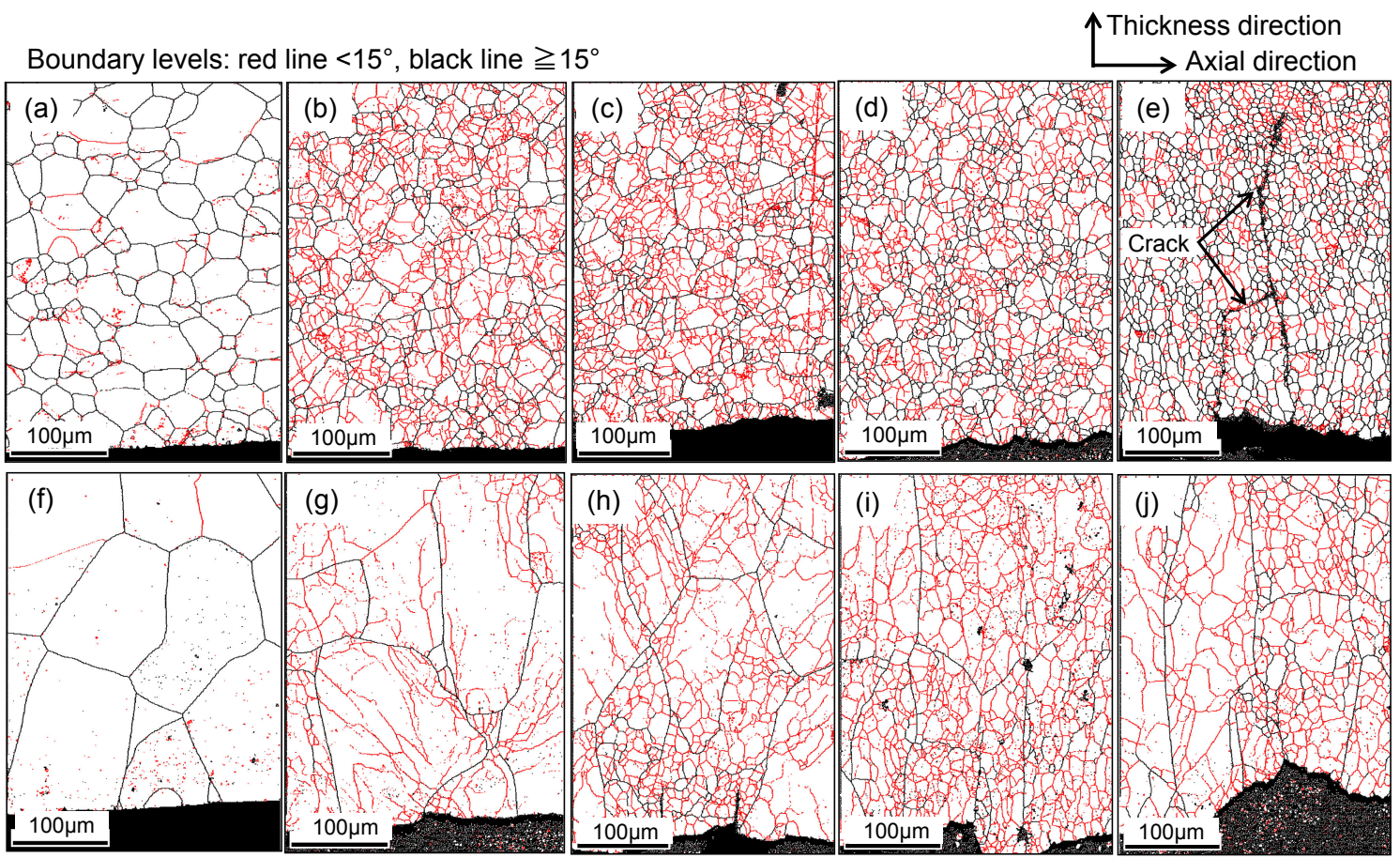

Fig. 8 Grain boundary maps obtained via EBSD measurements for the specimens with (a-e) fine grains and (f-j) coarse grains. (a, f) Maps before the thermal fatigue test. (b, g) Maps after 300 cycles. (c, h) Maps after 500 cycles. (d, i) Maps after 700 cycles. $(e, j)$ Maps after 1174 and 1000 cycles, respectively. The black and red lines are the high-angle boundary $\left(\geqq 15^{\circ}\right)$ and low-angle boundary $\left(<15^{\circ}\right)$, respectively.
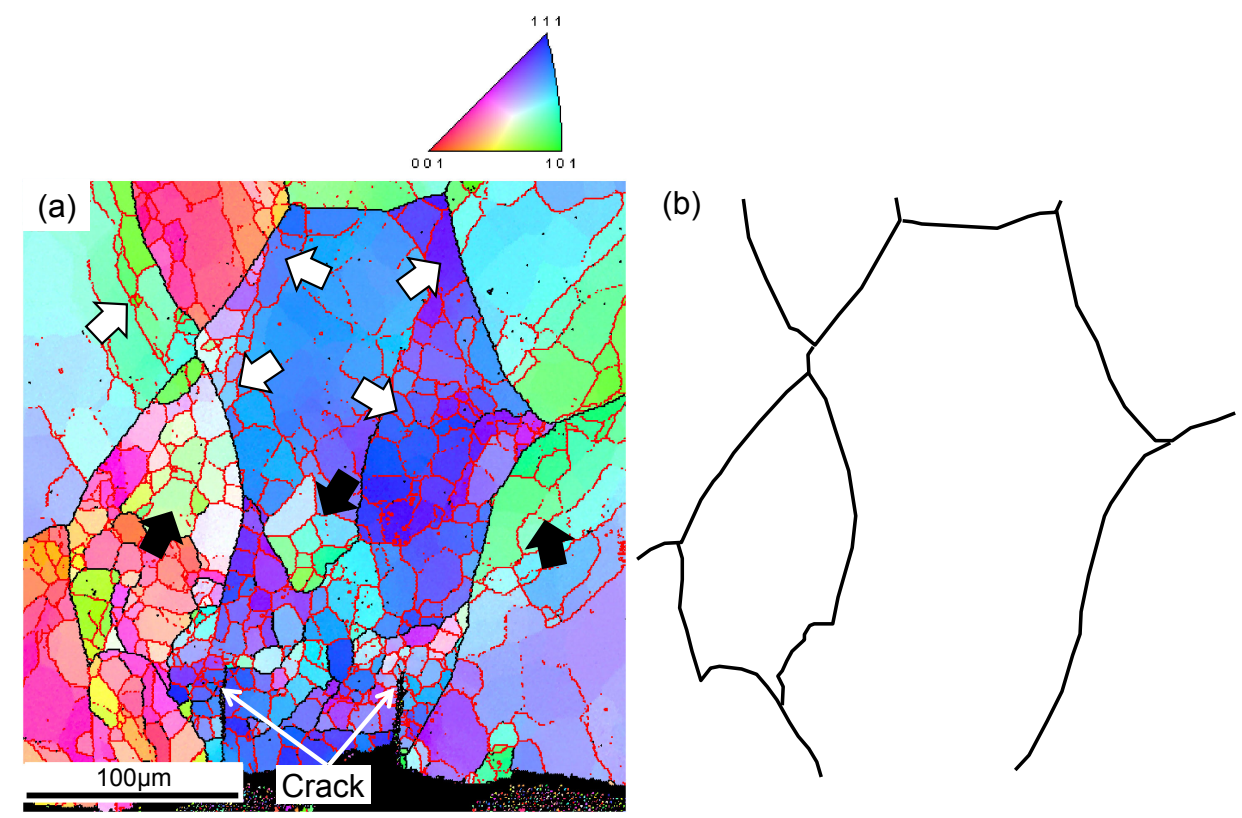

Fig. 9 (a) Inverse pole figure map obtained via EBSD measurements and (b) indication of initial grain boundaries for the coarse-grained specimen interrupted at 500 cycles. The black and red lines are the high-angle boundary $\left(\geqq 15^{\circ}\right)$ and low-angle boundary $\left(<15^{\circ}\right)$, respectively.

structure with low-angle boundaries observed in this study is different from that in general dynamic recrystallization. However, it seems, and therefore can be hypothesized, that the inhomogeneous recovery near the initial grain boundary in the coarse-grained specimen may be discontinuous. In addition, the thermal fatigue crack progressed in the initial grain interior in the coarse-grained specimen.

To quantitatively clarify the difference between the dynamic recovery and recrystallization with regard to the initial microstructure, i.e., the grain diameter, the changes in the frequency of low-angle boundaries are shown as functions of the number of cycles in Fig. 10. Here, the ratio of the low-angle boundary length to the total grain boundary length in the measured area was defined as the frequency of the low-angle boundary. As can be seen, in both specimens with 300 cycles, the frequencies of low-angle boundaries increased for both initial materials. This indicates progress of the formation of low-angle boundaries and subgrains by the 


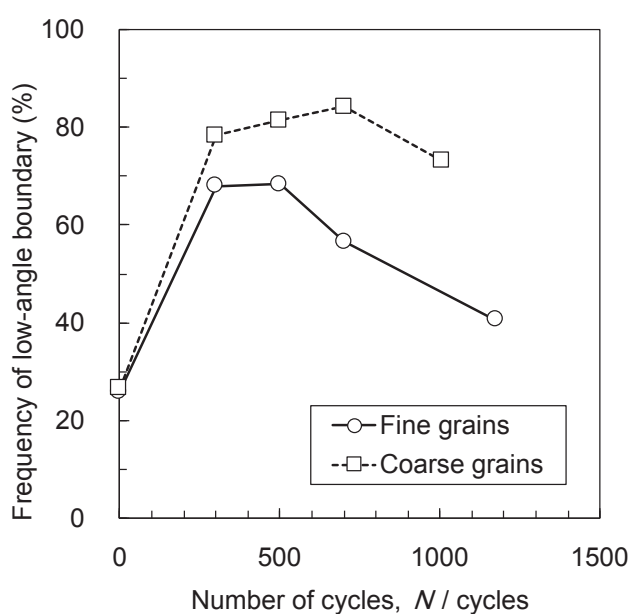

Fig. 10 Changes in the frequency of the low-angle boundary during the thermal fatigue process for the specimens with fine and coarse grains.

recovery, as observed in Figs. $8(\mathrm{~b})$ and $8(\mathrm{~g})$. In the case of fine-grained specimens, the frequency decreased after more than 500 cycles; this may be due to the occurrence of dynamic recrystallization. This tendency is similar to that reported in a previous study. ${ }^{15)}$ In contrast, in the case of a coarse-grained specimen, the frequencies increased to 700 cycles and decreased at 1000 cycles slightly, and the value was higher than that of the fine-grained specimen. Thus, dynamic recrystallization of the coarse grains in the initial microstructure is retarded during the thermal fatigue process. Conventionally, it is well known that the nucleation of new grains occurs at or near the grain boundaries in static and dynamic recrystallization. ${ }^{3-6)}$ Thus, it was confirmed that a similar phenomenon results in the thermal fatigue and that the changes in the microstructure depend on the initial grain size. It is thought that nucleation in the initial grain interior retarded in the case of coarse grains.

\subsection{Expression of dynamic recrystallization during the thermal fatigue process}

It is well known that dynamic recovery and recrystallization are quantified by the Zener-Hollomon parameter $Z$ described by eq. (1).

$$
Z=\dot{\varepsilon} \exp \left(-\frac{Q}{R T}\right)
$$

Here, $\dot{\varepsilon}$ is the strain ratio, $Q$ is the activation energy of high-temperature deformation, $R$ is the gas constant, and $T$ is the temperature. Considering $\dot{\varepsilon}=3 \times 10^{-5} \mathrm{~s}^{-1}$ (the strain ratio of the heating stage in this thermal fatigue test), $Q=$ $311 \mathrm{~J} / \mathrm{mol},{ }^{11)}$ and $R=8.31 \mathrm{~J} / \mathrm{mol} \cdot \mathrm{K}$ in eq. (1), we obtain $6 \times 10^{29}$ and $4 \times 10^{10} \mathrm{~s}^{-1}$ as $Z$ values at minimum $(473 \mathrm{~K})$ and maximum $(1073 \mathrm{~K})$ temperatures, respectively. In previous studies on ferritic steels, dynamic recrystallization was observed when the material was processed under a relatively low $Z$ condition. For example, Tsuji et al. ${ }^{11)}$ reported a condition wherein the dynamic recrystallization of Ti-added interstitial free ferritic steel occurred at $Z \leqq$ $10^{11} \mathrm{~s}^{-1}$ at a true strain of 0.8 . Yagi et al. ${ }^{12)}$ reported that dynamic recrystallization occurred at $Z \leqq 10^{14} \mathrm{~s}^{-1}$ at a true strain of 0.8 in high-purity $18 \% \mathrm{Cr}$ ferritic stainless steel.
Maki et al. $^{9)}$ found that dynamic recrystallization occurred in $16 \% \mathrm{Cr}$ ferritic stainless steel containing $0.02 \% \mathrm{C}$ at $Z \leqq$ $10^{9} \mathrm{~s}^{-1}$ at a true strain of 0.4 . Moreover, it is well known that dynamic recovery and recrystallization depend on not only the $Z$ parameter but also the strain. Murty et l. $^{22)}$ investigated the dynamic recrystallization of $0.15 \% \mathrm{C}$-added ferritic steel in detail, and a map showing the changes in the microstructure was created. According to their results, at a low $Z$ value, e.g., around $10^{12} \mathrm{~s}^{-1}$ the extent of dynamic recovery and partial recrystallization was higher than that at a true strain of approximately 0.5 . The new ultrafine grains generated due to dynamic recrystallization occurred at more than approximately 2.5 true strain. Moreover, they showed that the critical strain for initiation and the strain for the completion of recrystallization were given by eqs. (2) and (3), respectively.

$$
\begin{gathered}
\varepsilon_{c}=7.00 \times 10^{-3} Z^{0.15} \\
\varepsilon_{99 \%}=0.15 Z^{0.1}
\end{gathered}
$$

Here, $\varepsilon_{c}$ is the strain required for the initiation of new grains and $\varepsilon_{99 \%}$ is the strain required for the completion of new grain formation. When we extrapolate the above critical strains on a $Z$ factor of $4 \times 10^{10} \mathrm{~s}^{-1}$ at the maximum temperature $(1073 \mathrm{~K})$ in this experiment using the above equations, we obtain the values 0.3 and 1.7 for $\varepsilon_{c}$ and $\varepsilon_{99 \%}$, respectively. In this experimental condition of thermal fatigue, the inelastic strain as a true strain per cycle is very small for the fine-grained specimen $(0.0022)$ and coarsegrained specimen (0.0025), but if it is assumed that this small inelastic strain accumulates in each cycle, a very large strain is realized at the number of cycles corresponding to failure. The concrete accumulation of inelastic strains reaches 0.3 , 1.7 , and 2.2-2.4 with the true strain at 120-140 cycles, at $680-770$ cycles, and at the number of cycles to failure. These values do not reach the value (more over 4) corresponding to severe plastic deformation, ${ }^{7)}$ but it is expected that remarkably large strain acts around the cracks. As shown in Fig. 3, subgrains were clearly observed in the initial grain interior at 300 cycles and fine recrystallized grains were partially observed at 700 cycles. Thus, the relationship between the accumulation strain and $Z$ for dynamic recovery and recrystallization almost agrees with previously reported results. However, it is hypothesized that $Z$ and the critical strain for the occurrence of dynamic recrystallization also depend on the chemical composition and precipitation. In fact, Yagi et al. ${ }^{12)}$ reported that even at low $Z\left(Z \leqq 10^{14} \mathrm{~s}^{-1}\right)$, dynamic recrystallization did not occur under the condition in which a number of carbides precipitated in the initial grain boundaries and pinned the boundaries. Because most heatresistant ferritic stainless steels contain $\mathrm{Nb}$ and other elements for high-temperature strengthening, solute elements and precipitation are expected to affect the mechanism of dynamic recrystallization related to $Z$ and strain, and these must be examined in detail in the future.

\subsection{New grain diameter during the thermal fatigue process}

Figure 11 shows the inverse pole figure maps around the crack obtained via EBSD measurement for the fine- and coarse-grained specimens after 1174 and 1000 cycles, 


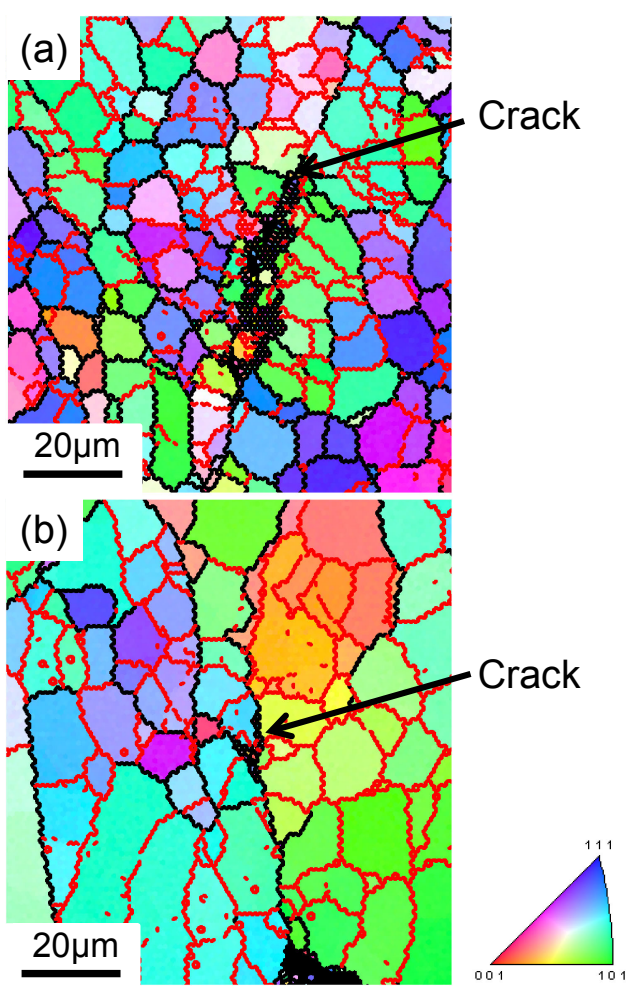

Fig. 11 Inverse pole figure maps obtained via EBSD measurements for the (a) fine-grained specimen at 1174 cycles and (b) coarse-grained specimen at 1000 cycles. The black and red lines are the high-angle boundary $\left(\geqq 15^{\circ}\right)$ and the low-angle boundary $\left(<15^{\circ}\right)$, respectively.

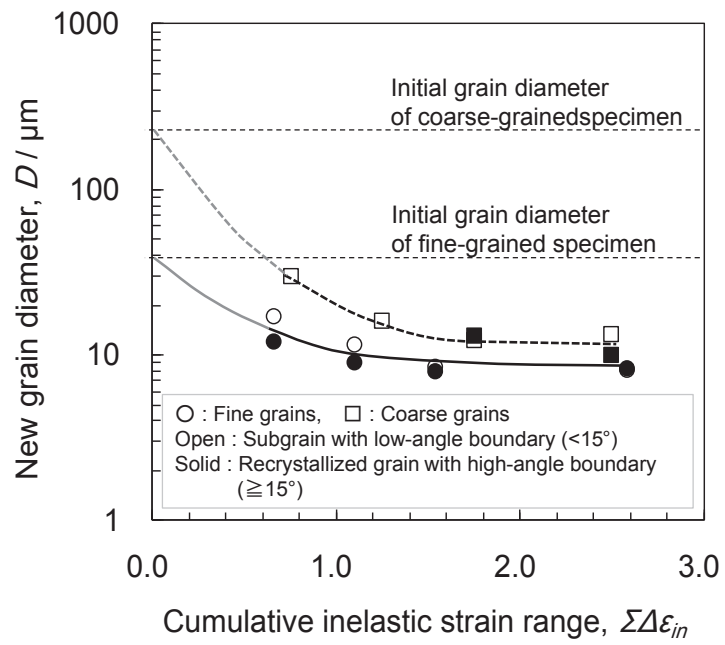

Fig. 12 Relationship between the cumulative inelastic strain range during thermal fatigue cycles and new grain diameters.

respectively. Compared to the fine-grained specimen, the coarse-grained specimen has coarse grains and low highangle boundaries after thermal fatigue. This may be caused by the density of the nucleation site depending on the initial grain size. Figure 12 shows the new grain diameters of the subgrains and recrystallized grains as functions of cumulative inelastic strain ranges. The diameters of new grains nucleated during the thermal fatigue process in the coarse-grained specimen seemed to be larger than those in the fine-grained specimen. However, the recrystallized grain size was approximately $10 \mu \mathrm{m}$ in both specimens and a saturation tendency was observed. Thus, although partial recrystallization was influenced by cracks and heterogeneous deformation, it is thought that the initial grain diameter dependence of the steady-state recrystallized grain size is small. Moreover, because the recrystallized grain size and subgrain size were almost the same, it is hypothesized that the dynamic recrystallization of this state with high cycles is relatively continuous. From this study, it was confirmed that dynamic recrystallization occurred in the thermal fatigue process during which the temperature and strain change repeatedly, and the formation of the microstructure was proved to be affected by the initial grain size. However, because it is expected that this behavior depends on the chemical composition and the thermal fatigue condition, further investigations are necessary.

\section{Conclusions}

To understand the effects of grain size on the thermal fatigue behavior and dynamic recrystallization during the thermal fatigue process in ferritic stainless steel, interrupted tests of thermal fatigue at a maximum temperature of $1073 \mathrm{~K}$ and a minimum temperature of $473 \mathrm{~K}$ with a restriction ratio $50 \%$ were conducted for fine-grained (diameter: $38 \mu \mathrm{m}$ ) and coarse-grained (diameter: $221 \mu \mathrm{m}$ ) specimens in an $\mathrm{Nb}$ and $\mathrm{Si}$-added ferritic stainless steel tube. The main results can be summarized as follows:

(1) Under the condition of thermal fatigue, the fine-grained specimen showed a small inelastic strain range during the thermal fatigue process and had a longer life than the coarse-grained specimen.

(2) From the observation of the microstructure using EBSD, it was confirmed that dynamic recovery and recrystallization occurred during the thermal fatigue process. The coarse-grained specimen showed lower nucleus density and retardation of the recrystallization during the thermal fatigue process in comparison with the fine-grained specimen.

(3) When we assumed that the inelastic strain accumulates during the thermal fatigue cycles, the relationship between the accumulated strain and $Z$ for dynamic recrystallization almost agreed with previously reported results. For the steady-state partially recrystallized grain size in high cycles, there was little initial grain size dependence.

\section{Acknowledgment}

We are grateful to Dr. N. Nakada, Tokyo Institute of Technology, for the fruitful discussions.

\section{REFERENCES}

1) T. Sakai: Bull. Jpn. Inst. Metalls 22 (1983) 1036-1045.

2) T. Maki and I. Tamura: Tetsu-to-Hagané 70 (1984) 2073-2080.

3) T. Sakai and J.J. Jonas: Acta Metall. 32 (1984) 189-209.

4) F.J. Humphreys and M. Hatherly: Recrystallization and Related Annealing Phenomena, (Pergamon, New York, 1995) pp. 363-392.

5) T. Sakai, A. Belyakov, R. Kailbyshev, H. Miura and J.J. Jonas: Prog. Mater. Sci. 60 (2014) 130-207.

6) T. Maki, K. Akasaka, K. Okuno and I. Tamura: Tetsu-to-Hagané 66 
(1980) 1659-1668.

7) T. Maki, T. Furuhara, N. Tsuji, S. Morito, G. Miyamoto and A. Shibata: Tetsu-to-Hagané 100 (2014) 1062-1075.

8) G. Glover and C.M. Sellars: Metall. Trans. 4 (1973) 765-775.

9) T. Maki, S. Okaguchi and I. Tamura: Proc. of Int. Conf. on Strength of Metals and Alloys (ICSMA6), (Pergamon, Oxford and New York, 1982) pp. 529-534.

10) A. Najafi-Zadeh, J.J. Jonas and S. Yue: Metall. Trans. A 23 (1992) 2607-2617.

11) N. Tsuji, Y. Matsubara, Y. Saito and T. Maki: J. Jpn. Inst. Met. 62 (1998) 967-976.

12) H. Yagi, N. Tsuji and Y. Saito: Tetsu-to-Hagané 86 (2000) 349-356.

13) H. Kajimura: Bull. Iron Steel Inst. Jpn. 11 (2006) 67-73.

14) J.-I. Hamada, H. Kajimura and N. Morihiro: Proc. of 6th European Stainless Steel Conference, (JERNKONTORET, Stockholm, 2008) pp. 669-674.

15) J.-I. Hamada, N. Morihiro and H. Kajimura: J. Jpn. Inst. Met. 81 (2017) 527-535.

16) Y. Tarutani, K. Higuchi, T. Matsuda, M. Miyahara and N. Hiraide: Sumitomo Met. 47 (1995) 76-79.

17) N. Fujita: Shinnittetsu Giho 371 (1999) 30-34.

18) J.-I. Hamada, A. Hayashi, N. Kanno, T. Komori, K. Ito, N. Fukuda and Y. Inoue: Materia Japan 56 (2017) 33-35.

19) J.-I. Hamada, N. Kanno, A. Hayashi, N. Hiraide, M. Abe, K. Nishimura, C. Takushima, A. Yakawa and F. Fudanoki: Metall. Ital. 4 (2018) 33-39.

20) S. Taira and M. Fujino: J. Soc. Mater. Sci. Jpn. 25 (1976) 218-229.

21) T. Maki: CAMP-ISIJ 19 (2006) 410-413.

22) S.V.S.N. Murty, S. Torizuka, K. Nagai, N. Koseki and Y. Kogo: Scr. Mater. 52 (2005) 713-718. 